\title{
Study on the Teaching Mode of Professional Physique in Jilin Higher Vocational Colleges*
}

\author{
Honglin Zhao \\ Jilin Engineering Normal University \\ Changchun, China 130052
}

\begin{abstract}
The development of professional physique education in higher vocational colleges should follow its own characteristics and development rules. The professional physical education in vocational colleges has its own characteristics and development rules. It is necessary to take professional physique education as a kind of long-term construction mechanism, increase the construction of sports facilities and the scientific research investment in teaching reform, strengthen the research on the majors and physical characteristics of students in higher vocational colleges, formulate the teaching syllabus in line with the professional physique characteristics of higher vocational colleges, define the curriculum standards, and establish the teaching system from the practical and professional perspectives.
\end{abstract}

Keywords-higher vocational colleges; professional physique; teaching mode

\section{INTRODUCTION}

Higher vocational education is an important part of China's higher education, which aims at cultivating advanced application-oriented talents working on the front line of production, construction, management and service. With the development and progress of the society, different social occupational division of labor has different requirements on the quality of workers.

Higher vocational education is the last station before students stepping into the society. Higher vocational physical education is an important way to enhance students' physique, cultivate students' awareness of lifelong exercise and enhance their professional physical fitness. However, the rapid development of vocational colleges in recent years, the increase enrollment of students, insufficient teaching equipment, the lack of teachers, teaching philosophy differences, are restricting the development of physical education. At present, the teaching mode of higher vocational physical education in Jilin Province is basic course plus optional course or optional course without basic course. Few schools try to reform the teaching according to the students' professional characteristics in physical education. Such practice not only deviates from the education theory of higher vocational colleges, but also makes students' understanding of sports only stay at the level of general interests and physical fitness, and fail to truly

*Fund: The 13th Five-year Social Science Research Program of Jilin Provincial Education Department (Project No.: 2016094). realize the far-reaching impact on their future career and life. Secondly, the content of physical education in higher vocational colleges is almost the same as that in ordinary colleges. The methods adopted are mainly to enhance students' physique, ignoring the characteristics of students' vocational skills, which fails to fully reflect the requirements and characteristics of higher vocational physical education. Therefore, it is an important problem for the reform of physical education in higher vocational colleges to construct professional physique education on the basis of normal professional physique education in higher vocational colleges so that students can be physically qualified for the needs of future careers.

The model that analyzes the physical requirements of students of different majors, proposes targeted teaching methods and means to encourage students prepare for their future work physically in the present stage, and to promote them to master the methods of self-exercise and self-care can both reach the goal of higher vocational physical education, and lay a foundation for students to establish lifelong exercise and better serve the socialist modernization construction in the future.

\section{The Connotation of Professional PhysiQue}

Professional physique is the general term for the physical fitness of athletes, that is, the maximum level of physical exertion of athletes in special competitions. It indicates the level of anaerobic training and aerobic training and reflects the level of energy metabolism of athletes. Physical ability is the body's ability to adapt to its environment. This includes health related fitness and exercise related fitness. The definition of "physical ability" in Sports Dictionary published by Shanghai Lexicographical Publishing House and New Dictionary of Modern Chinese published by China Women Publishing House is as follows: Physical ability refers to the ability of various organ systems of the human body to perform physical activities. It covers basic physical qualities such as strength, speed, agility, endurance, and flexibility, as well as basic physical abilities (such as walking, running, jumping, throwing, climbing, creeping, overhanging, and planking). 


\section{Helping Students Build up the Awareness of Lifelong Sports}

The aim of physical education teaching is to master the basic technology and skills of physical education, the basic knowledge of physical health care, and establish the idea of lifelong exercise, which enables students consciously and voluntarily exercise after entering the society. PE teaching in higher vocational colleges is the last station for students to receive systematic PE teaching. After graduation, students will take part in the first line of production work. With the development of modern science and technology, great changes have taken place in people's production and way of life. The large, high-intensity labor movements of the past have been replaced by small movements involving small groups of muscles. It requires people to control the production process flexibly, accurately and harmoniously, and to judge and process the data of many instruments quickly and accurately, and sometimes it requires holding breath, staring at the screen or looking intently. All this causes the worker's cerebral cortex to be highly concentrated for a long time during production. Such concentration is more demanding and fatiguing than mere muscular activity. Therefore, it is imperative to master the physical training methods and sports knowledge suitable for this major in the physical education of higher vocational colleges. In addition to strengthening the physical training methods and scientific knowledge education which are closely related to the characteristics of vocational and technical education, the development of vocational practical physical education should also attach importance to the idea of lifelong physical education and cultivate students' lifelong physical education consciousness. In this way, students can continue to consciously engage in physical exercise according to the changes of subjective and objective conditions after graduation, which will lay a solid physical foundation for future work and life.

\section{The MaIn PRoblems of Vocational PHYSICAL EDUCATION IN HighER VOCATIONAL COLLEGES IN JILIN PROVINCE}

\section{A. School Leaders Don't Pay Enough Attention to Physical Education}

Most higher vocational schools are upgraded or merged from the original technical secondary or technical schools. Although the school level has been raised, the school leaders have not considered the importance of physical education from a strategic height, and have not paid enough attention to physical education, which has affected the effect of physical education and health education. Higher vocational colleges cultivate application-oriented talents. After graduation, students are more likely to work in the first line of production, which requires them to have specific occupational physical qualities. However, the teaching objectives of physical education and health in many higher vocational colleges do not reflect this point, which is completely out of touch with the future career needs of students in higher vocational colleges. 


\section{B. Teachers Do Not Have a Thorough Understanding of Relevant Majors}

Vocational physical is set for students' relevant majors, and has a direct relationship with students' majors. Although the physical requirements of students of different majors and genders have certain commonalities, they also have their special personalities. Only by following the rules of physical development can students' physical development be better promoted. The physical education in higher vocational colleges should put the cultivation of students' vocational physical ability in the first place. Teachers must understand and be familiar with the characteristics of the students' majors. The teaching content should be arranged according to the actual needs of students' majors, and physical education should be carried out appropriately after the completion of basic teaching tasks. It's also necessary to focus on cultivating their adaptability, survival ability. Most schools offer basketball, volleyball, football, track and field, table tennis, badminton, aerobics and so on. The content of physical education related to students' future career is rarely covered.

\section{There Is No Clear Physical Education System}

For a long time, the physical education of higher vocational colleges follows the education system of undergraduate course, and most higher vocational colleges adopt the unified teaching material issued by the Ministry of Education. The discipline system of sports and the teaching of sports technology are emphasized. In the future, students who step into the front-line positions of production, construction, management and service need classroom teaching that is close to reality or in line with reality. Physical education in higher vocational colleges not only gives full play to its health attributes, but also focuses on cultivating vocational attributes, combining the professional characteristics and the professional characteristics of the students in the future, to develop the physical and mental qualities needed for the occupation after graduation, enhance the competitiveness of the students, so that students can adapt to the job as soon as possible.

\section{CARrying OUT PHYSicAl EdUCATION TEACHING IN ACCORDANCE WITH VOCATIONAL PHYSICAL EDUCATION}

The ultimate goal of higher vocational education is to train practical talents who can adapt to the production of modern society. Most students in higher vocational colleges work in the front line after graduation, while different occupational positions have different objective requirements on physical quality. In the process of physical education teaching, it is necessary to carry out vocational physical training, cultivate students' basic physical activity ability and adaptability to the environment, so that they can directly serve the future career. Otherwise, the quality of vocational and technical learning will be reduced, the improvement of labor skills will be affected, and vocational labor tasks are even difficult to complete. Integrating professional physical training into physical education enables students to understand the professional characteristics of their major in the future, as well as the psychological and physiological load, working style, movement speed, tension, strength, concentration, etc. in the process of labor, which will help students adapt to the new working environment quickly after they enter the work position, help them better engage in productive labor, and thus provide more and better services to the society.

\section{A. Physical Education Teaching Content Should Adapt to the Professional Characteristics}

Physical education teaching content should be in line with professional characteristics, and is helpful to train future workers' ability to use technology and sports related knowledge. At the same time, it should also meet the requirements of the special physical qualities required by the occupation. Movement characteristics should be consistent with the occupational skills and physical fitness. The selected actions can be targeted to prevent and correct the adverse effects of occupational habits on the human body. This is consistent with the teaching objectives of higher vocational colleges.

\section{B. The Goal of Physical Education Teaching Should Be Consistent with the Professional Characteristics}

Teaching objective is the starting point and end-result of teaching reform, and it is the explicit explanation of the learning results or final behavior of students. All teaching activities are carried out and developed around teaching objectives. Therefore, the PE teaching objectives of higher vocational colleges should be in line with the professional characteristics:

It's needed to actively participate in a variety of physical activities and form a conscious exercise habit, work out feasible individual exercise plan, carry out physical exercise scientifically, improve sports ability, and have certain ability to appreciate sports culture.

It's needed to master more than two basic methods and skills in fitness exercises, master the physical training methods required by occupational characteristics, and master the treatment of common sports injuries.

It's needed to test and evaluate physical health status, master the methods to effectively develop occupational physical fitness, occupational special physical fitness, occupational quality and occupational health care according to individual professional characteristics and future occupational characteristics, and develop a healthy lifestyle and good behavior.

It's needed to improve the psychological state, overcome psychological barriers, and to develop a positive and optimistic attitude towards life through physical activities, use appropriate methods to regulate their own emotions, experience the fun of sports and the feeling of success in sports, and cultivate the thought of "lifelong sports". 
C. Reforming the Methods for Assessing Athletic

Performance in Which Both Athletic Skills and Physical Ability Should Be Evaluated

The assessment and evaluation of physical education is for the purpose of teaching, which is to promote students' learning, improve their learning efficiency and serve their lifelong development. The content and method of physical education evaluation in higher vocational colleges should consider the characteristics of vocational education while centering on the objective of physical education. According to the requirements of vocational education, in order to meet the demands of modern vocational labor on the quality of laborers, the evaluation should focus on the special physical energy required by the occupation and the sports skills that can promote the occupational operation skills. The content of evaluation includes four aspects: theoretical knowledge, physical quality, sports technique and normal performance and arrange the proportion of each item according to different projects.

\section{CONCLUSION}

Under the condition of fierce market competition, only by innovating the teaching system and cultivating talents to meet the needs of the society can higher vocational colleges remain invincible. This requires not only talent training with scientific orientation, but also employment-oriented professional technical skills and occupational physical fitness. Therefore, it's a must to pay attention to the comprehensive cultivation of students' physical ability in daily teaching. While ensuring the basic knowledge and technical teaching, it's imperative to improve students' vocational physical ability, so that students' comprehensive quality can be improved and they have a significant competitive advantage and are favored by employers.

\section{REFERENCES}

[1] Lin Guichi. Practical Teaching Methodology in Physical Education in Vocational Colleges [J]. Shandong Sports Science \& Technology. 2009(1):71. (in Chinese)

[2] Xue Jian'ai. The Research on Adaptability of PE Teaching with Professional Characteristics at Demonstration Higher Vocational Colleges of Shanxi [D]. Xinjiang Normal University. 2012: 8. (in Chinese)

[3] Zhao Honglin, Zhang Xuesheng. Pondering on Implementing Vocational Physical Teaching in Higher Vocational Schools [J]. Vocational and Technical Education. 2012(17):61. (in Chinese)

[4] Zhang Huihong. PE Course Resources System Theory and Its Application in College PE Courses: An Empirical Study [D]. Fujian Normal University, 2006: 9. (in Chinese)

[5] Hou Xin. Research on the Combination of Physical Education Curriculum Reform and Vocational Skills in Higher Vocational Colleges in Dezhou City [D]. Shandong Normal University. 2010:7. (in Chinese)

[6] Liu Yi. The Evolution and the Reform of College PE Courses Since New People's of China Set up [D]. Henan University, 2007: 6. (in Chinese) 